\title{
O PROBLEMA DA REPRESENTAÇÃO DAS FUTURAS GERAÇÕES NO ENDIVIDAMENTO PÚBLICO: REPERCUSSÕES PARA O PRINCÍPIO JURÍDICO DE EQUILÍBRIO INTERGERACIONAL
}

\section{Luis Felipe Vidal Arellano}

Mestre em Direito Penal e Doutor em Direito Econômico e Financeiro pela Faculdade de Direito da Universidade de São Paulo (USP). Pós-Graduado em Análise Econômica pela Fundação Instituto de Pesquisas Econômicas (FIPE/USP) e MBA em Gestão Avançada de Finanças Públicas pela Fundação Dom Cabral (FDC). Foi Subsecretário do Tesouro do Município de São Paulo (2014-2018) e é atualmente Secretário de Fazenda Adjunto do Município de São Paulo.

\section{SUMÁRIO}

Introdução - 1. Brevíssima discussão sobre regras e princípios -2 . Existe o princípio jurídico de equilíbrio intergeracional? - 3. O mecanismo de deslocamento dos gastos pelo endividamento - 4. A competição intergeracional como tragédia - Conclusões - Referências. 


\section{INTRODUÇÃO}

A teoria microeconômica confere ao sistema de preços um importante papel, qual seja o de mecanismo eficiente de alocação de recursos, conforme as preferências individuais. Por meio da sinalização do preço, os bens seriam alocados a cada um, conforme as suas preferências relativas. Um pressuposto de funcionamento deste sistema é que cada um pague por aquilo que consome, pressuposto este ausente quando se trata tanto de subsídios públicos quanto do diferimento dos custos e benefícios dos gastos públicos no tempo ou deslocamento desses custos e benefícios no espaço e no tempo. Nestes casos, pode ocorrer um descasamento entre aqueles cidadãos que financiam o gasto e aqueles que dele se beneficiam ${ }^{1}$.

O objetivo do presente trabalho é discutir o problema da representação das futuras gerações no endividamento público e a existência de um princípio jurídico de equilíbrio intergeracional. A partir dessa discussão, busca-se se situar o papel do direito financeiro no asseguramento dos interesses das futuras gerações, em face das ações das gerações presentes.

\section{BREVÍSSIMA DISCUSSÃO SOBRE REGRAS E PRINCÍPIOS}

O problema da sub-representação das futuras gerações em decisões envolvendo as aplicações de recursos do Estado e seus efeitos no longo prazo se insere

1 FERREIRA, Ivan Fecury Sydrião. A Economia Política do Endividamento Público em uma Federação: um estudo comparativo entre o Brasil e os Estados Unidos, p. 1: "A introdução do mecanismo do endividamento para financiar estes gastos acrescenta à consideração de equidade geográfica, a equidade intertemporal. Muitos dos bens e serviços que são providos pelos Estados e Municípios são despesas de capital que resultam em projetos que possuem uma vida útil, e que portanto, oferecem retomo à população durante todo esse período. A consideração de equidade intertemporal sugere que, para evitar o surgimento do "free rider', o pagamento desses projetos deve ser efetuado durante o seu período de vida útil. Quando um projeto é integralmente financiado com dívidas, que são roladas indefinidamente, as gerações presentes se beneficiam do projeto, enquanto que as gerações futuras poderão ficar exclusivamente com as dívidas, caso a vida útil do projeto já tenha se esgotado.” E continua na página 8: “A discussão sobre endividamento mostra uma constante tensão existente entre as gerações presentes e futuras. As gerações futuras são naturalmente impossibilitadas de efetivamente se fazerem representar nas decisões tomadas pelas gerações presentes. Elas não, podem expressar as suas opiniões nem exercer o direito do voto e, consequentemente, não podem escolher os seus representantes. Devido a isso, existe uma tendência de que, na inexistência de um conjunto de leis que protejam os interesses das gerações futuras, os representantes políticos das gerações presentes transfiram uma pesada carga de dívida para aquelas gerações, com o intuito de obter ganhos políticos imediatos." 
na possibilidade que a dívida pública traz de deslocamento do tempo de custos e benefícios da ação financeira do Estado ${ }^{2}$.

Argumenta-se que o tempo de duração de um mandato político gera incentivos ao comportamento oportunista do governante, que tem o interesse de incorrer em déficits durante o seu mandato, para que sejam pagos futuramente, por outros mandatários. Há, porém, impedimentos a este comportamento de ordem econômica e institucional ${ }^{3}$.

Entre os impedimentos de ordem econômica, encontram-se as restrições impostas pelo próprio Mercado, que, presumivelmente, identifica esse comportamento como irresponsável diminuindo a demanda por títulos de dívida de um ente estatal com tal comportamento ${ }^{4}$. Encontra-se também a preocupação com a inflação como um óbice de mercado ao comportamento oportunista, visto que elevados déficits públicos poderiam ser futuramente custeados com receita de senhoriagem, isto é, com emissão de moeda ${ }^{5}$, em prejuízo à toda economia.

Com relação aos impedimentos de ordem institucional, temos as regras jurídicas que impõem limites de endividamento, metas fiscais relacionadas a déficit, transparência da política de endividamento público, assim como as instituições

2 PAZ FERREIRA, Eduardo M. H. Da dívida pública e das garantias dos credores do Estado, p. 69: "Qualquer decisão financeira, quer se trate de um a escolha de quais as necessidades a satisfazer por forma pública, quer dos meios a utilizar para tal satisfação tem, necessariamente, reflexos sobre as gerações futuras, não só porque altera a distribuição dos recursos disponíveis entre o sector público e o privado, como também pelas modificações que pode determinar no comportamento dos agentes económicos e que são susceptíveis de se repercutirem sobre o montante e a composição do património que esses agentes irão transmitir aos seus herdeiros.”

3 GIAMBIAGI, F.; ALÉM, A. Finanças Públicas: teoria e prática no Brasil, p. 218: “... no cálculo político do governante, o horizonte de tempo relevante é o da sua permanência no cargo. É claro que, se não houvesse restrições, então os governos gerariam déficits altíssimos e se endividariam ad infinitum."

4 GIAMBIAGI, F.; ALÉM, A. Idem ibdem. "Quais são as restrições, então, que operam e limitam o déficit e o endividamento público? Há três que são relevantes. A primeira é o mercado. Para que haja uma dívida, é preciso que exista um credor. Um devedor que sistematicamente deixe de honrar seus compromissos, mais cedo ou mais tarde, enfrentará a hostilidade do mercado, que lhe negará o acesso a novas fontes de endividamento."

5 GIAMBIAGI, F.; ALÉM, A. Idem ibdem. "A segunda restrição é o risco de inflação: se o déficit for elevado e não houver como financiá-lo através da colocação de novos títulos, só restará ao governo a alternativa de fazer isso através da emissão monetária. Esta, porém, ao gerar uma expansão dos meios de pagamento muito superior ao aumento da quantidade de bens e serviços da economia, tenderá, mais cedo ou mais tarde, a se refletir no nível de preços.” 
de controle perenes, tais como os tribunais de contas $^{6}$. Nesta ordem de instrumentos, a Lei de Responsabilidade Fiscal (LRF - Lei Complementar n. 101/2000) representa a pedra fundamental. Deixaremos, porém, de nos aprofundar sobre estes instrumentos, por não serem o objeto central do presente trabalho.

O objetivo central do presente trabalho é discutir o problema da representação das futuras gerações no endividamento público e a existência de um princípio jurídico de equilíbrio intergeracional. Para tanto, mostra-se essencial uma breve introdução ao tema jusfilosófico a respeito da divisão das normas jurídicas em regras e princípios, apenas com a finalidade de situar o leitor no arcabouço teórico utilizado neste trabalho.

Além de regras, o direito é composto por princípios, conforme a crítica de Ronald Dworkin ao positivismo jurídico predominante até a sua formulação jurídica. Tais princípios entram em cena, especialmente, diante dos chamados hard cases ou seja, dos casos para os quais as regras existentes na ordem jurídica não se amoldam de maneira perfeita, devendo o juiz julgar com base em valores?

Segundo Humberto Ávila, os casos difíceis (hard cases) aparecem apenas na aplicação das regras, devido a avaliação da aplicação de uma determinada regra a um caso concreto, em razão da situação fática ser interpretada como amoldada a descrição da hipótese de incidência da norma, sem que, contudo, esta aplicação contribua para o atingimento da finalidade mediata da regra ${ }^{8}$. No caso dos princípios, por outro lado, ao intérprete caberia demonstrar argumentativamente a

6 GIAMBIAGI, F.; ALÉM, A. Idem ibdem. "Finalmente, a terceira restrição é dada pelo conjunto de instituições em que se insere a implementação da política fiscal. Cabe esperar que sociedades com economias desenvolvidas, maior nível de bem-estar social, instituições maduras e certa dose de responsabilidade da parte dos seus dirigentes, criem mecanismos de contrapeso que entrem em ação se, em determinado momento, o déficit público se mostrar perigosamente elevado.”

7 WACKS, Raymond. Philosophy of law: a very short introduction, p. 69: "Thus, for Dworkin, law consists not merely of rules, as Hart contends, but includes what Dworkin calls non-rules standards - principle and policies - in order to reach a decision. No rule of recognition -as described by Hart and discussed in the last chapter - exists to distinguish between legal and moral principles. Deciding what the law is depends inescapably on moral-political considerations."

8 ÁVILA, Humberto. Teoria dos princípios: da definição à aplicação dos princípios jurídicos, p. 97: "Se a construção conceitual do fato, embora corresponda a construção conceitual da descrição normativa, não se adequar a finalidade que lhe dá suporte ou for superável por outras razões, o ônus argumentativo é muito maior. São os chamados casos difíceis.” 
correlação entre a conduta ou comportamento analisado e o estado de coisas perseguido pelo princípio9.

Esse abandono em relação à tese positivista da estrita separação entre Moral e Direito é decorrência da compreensão do Direito por Dworkin como uma atividade principalmente interpretativa, baseada na interpretação dos aplicadores do Direito a respeito do sistema político e de decisões de uma determinada comunidade ${ }^{10}$.

Princípios são imperativos de maximização, que podem conflitar com outros princípios, sem que um deles seja considerado inválido, ao contrário das regras. Também ao contrário das políticas, os princípios não remetem a objetivo a ser atingido, mas sim a um senso de justiça ou fairness ${ }^{11}$. A principal distinção entre princípios e regras consiste no fato de que os princípios remetem a um estado de coisas a ser atingido, ao passo que as regras são imediatamente descritivas de um comportamento a ser seguido, sendo apenas mediatamente finalísticas ${ }^{12}$.

9 ÁVILA, Humberto. Op. cit., p. 98: "No caso dos princípios, o elemento descritivo cede lugar ao elemento finalístico, devendo o aplicador, em razão disso, argumentar de modo a fundamentar uma avaliação de correlação entre os efeitos da conduta a ser adotada e a realização gradual do estado de coisas exigido. Como não se trata de demonstração de correspondência, o ônus argumentativo é estável, não havendo casos fáceis e casos difíceis."

10 WACKS, Raymond. Idem, ibdem. "In a hard case the judge therefore draws on principles, including his or her own conception of the best interpretation of the system of political institutions and decisions of the community. 'Could my decision', he or she must ask, 'form part of the best moral theory justifying the whole legal and political system?' There can only be one right answer to every legal problem; the judge has the duty to find it. His or her answer is 'right' in the sense that it fits best with the institutional and constitutional history of his or her society and is morally justified. Legal argument and analysis are therefore 'interpretative' because they attempt to make the best moral sense of legal practices."

11 WACKS, Raymond. Op. cit., p. 71: "Dworkin claims that, while rules 'are applicable in an all-or-nothing fashion, principles and policies have 'the dimension of weight or importance'. In other words, if a rule applies, and it is a valid rule, a case must be decided in a way dictated by the rule. A principle, on the other hand, provides a reason for deciding the case in a particular way, but it is not a conclusive reason: it will have to be weighed against other principles in the system. Principles differ from policies in that the former is a 'standard to be observed, not because it will advance or secure and economic, political, or social situation, but because it is a requirement of justice or fairness or some other dimension of morality'. A 'policy', however, is 'that kind of standard that sets out a goal to be reached, generally an improvement in some economic, political, or social feature of community."

12 ÁVILA, Humberto. Op. cit., p. 95: "As regras podem ser dissociadas dos princípios quanto ao modo como prescrevem o comportamento. Enquanto as regras são normas imediatamente descritivas, na medida em que estabelecem obrigações, permissões e proibições mediante a 
Para uma definição mais precisa nos valemos das palavras de Humberto Ávila ${ }^{13}$, para quem:

As regras são normas imediatamente descritivas, primariamente retrospectivas e com pretensão de decidibilidade e abrangência, para cuja aplicação se exige a avaliação da correspondência, sempre centrada na finalidade que lhes dá suporte ou nos princípios que lhes são axiologicamente sobrejacentes, entre a construção conceitual da descrição normativa e a construção conceitual dos fatos.

Os princípios são normas imediatamente finalísticas, primariamente prospectivas e com pretensão de complementaridade e de parcialidade, para cuja aplicação se demanda uma avaliação da correlação entre o estado de coisas a ser promovido e os efeitos decorrentes da conduta havida como necessária à sua promoção.

Um grande problema decorrente da não distinção de maneira rigorosa dos conceitos de princípios e de regras é do da arbitrariedade que muitas vezes se verifica na formação dos conteúdos dos princípios, justificando-se na maior subjetividade interpretativa que estes autorizariam em relação àquela presente nas regras ${ }^{14}$.

Por essa razão, o recurso aos princípios como fundamento para a decisão deve ser precedido de rígida formulação teórica, que permita a adoção de critérios objetivos e controláveis de ponderação de princípios e de sua utilização para in-

descrição da conduta a ser adotada, os princípios são normas imediatamente finalísticas, já que estabelecem um estado de coisas para cuja realização e necessária a adoção de determinados comportamentos. Os princípios são normas cuja qualidade frontal é, justamente, a determinação da realização de um fim juridicamente relevante, ao passo que a característica dianteira das regras e’ a previsão do comportamento.” E na página 96: “Já as regras podem ser definidas como normas mediatamente finalísticas, ou seja, normas que estabelecem indiretamente fins, para cuja concretização estabelecem com maior exatidão qual o comportamento devido; e, por isso, dependem menos intensamente da sua relação com outras normas e de atos institucionalmente legitimados de interpretação para a determinação da conduta devida."

13 Op. cit., p. 102.

14 ÁVILA, Humberto. Op. cit., p. 111: "Essa contradição interna da doutrina não diz respeito a uma mera questão de nomenclatura, de resto secundaria. Tratar-se-ia de uma disputa terminológica se não surgissem dois problemas fundamentais: de um lado, se não fossem atreladas às normas comentadas determinadas propriedades que elas, em verdade, não têm - alto grau de generalidade e abstração; de outro, se não fosse atrelada a definição das referidas normas uma consequência específica para a sua aplicação - alto grau de subjetividade. Sendo essas as características, a doutrina, de um lado, cai em contradição e, de outro - o que é bem pior -, legitima a flexibilização na aplicação de uma norma que a Constituição, pela técnica de normalização que utilizou, queria menos flexível.” 
terpretação da amplitude do sentido normativo de regras. Do contrário, abre-se uma porta ampla para o arbítrio e o decisionismo ${ }^{15}$.

Os princípios apresentam tanto eficácia interna quanto externa. A primeira diz respeito ao seu papel para a compreensão do sentido das próprias normas. Já a eficácia externa diz respeito ao papel dos princípios na compreensão dos sentidos dos fatos, em um determinado contexto, e da avaliação da sua real subsunção às normas ${ }^{16}$.

A eficácia externa dos princípios impõe ao Estado, quanto aos princípios que estabelecem proibições de intervenção em liberdades públicas, verdadeiro direito subjetivo dos cidadãos. Daí decorrem a função de defesa e a função protetora dos princípios $^{17}$.

No caso do endividamento público, poderíamos colocar em perspectiva o conflito geracional no sentido de um conflito entre princípios que definem direitos da futura geração, tais como o princípio da responsabilidade fiscal e do equilíbrio orçamentário intertemporal, e políticas formadas pela geração presente, que defi-

15 ÁVILA, Humberto. Op. cit., p. 149: “(...) Esclareça-se que defender a ponderação sem, ao mesmo tempo e de saída, apresentar os critérios intersubjetivamente controláveis para sua aplicação, é legitimar doutrinariamente a sua utilização excessiva e arbitrária, de nada valendo a constatação tardia do seu desvirtuamento.

As considerações precedentes demonstram, pois, que o problema da aplicação do Direito não está apenas em analiticamente separar as espécies normativas, mas em municiar o aplicador de critérios, intersubjetivamente aplicáveis, que possam tornar efetivos os comandos normativos sem a incorporação do arbítrio."

16 ÁVILA, Humberto. Op. cit., p. 122: "As normas atuam sobre as outras normas do mesmo sistema jurídico, especialmente definindo-lhes o seu sentido e o seu valor. Os princípios, por serem normas imediatamente finalísticas, estabelecem um estado ideal de coisas a ser buscado, que diz respeito a outras normas do mesmo sistema, notadamente as regras. Sendo assim, os princípios são normas importantes para a compreensão do sentido das regras.” E na página 125: "Neste ponto, entra em cena a noção de eficácia externa: as normas jurídicas são decisivas para a interpretação dos próprios fatos. Não se interpreta a norma e depois o fato, mas o fato de acordo com a norma e a norma de acordo com o fato, simultaneamente."

17 ÁVILA, Humberto. Op. cit., p. 128: "Relativamente aos sujeitos atingidos pela eficácia dos princípios, é preciso registrar que os princípios jurídicos funcionam como direitos subjetivos quando proíbem as intervenções do Estado em direitos de liberdade, qualificada também como função de defesa ou de resistência (Abwehrfunktion).

Os princípios também mandam tomar medidas para a proteção dos direitos de liberdade, qualificada também de função protetora (Schutzfunktion). Ao Estado não cabe apenas respeitar os direitos fundamentais, senão também o dever de promovê-los por meio da adoção de medidas que os realizem da melhor forma possível.” 
nem objetivos para o futuro ${ }^{18}$. Quando há competição entre princípios e políticas, é preciso lembrar que, na lição de Dworkin, os princípios se refletem em direitos e, assim, devem se sobrepor aos objetivos, que são os reflexos das políticas.

\section{EXISTE O PRINCIIPIO JURIIDICO DE EQUILÍBRIO INTERGERACIONAL?}

O direito das futuras gerações a uma economia equilibrada é decorrência do princípio fundamental da igualdade entre os cidadãos, de indiscutível existência diante do artigo $5^{\circ}$, caput da Constituição Federal. De outro modo, se fosse possível estabelecer uma hierarquia entre os interesses dos cidadãos do presente com os cidadãos das gerações futuras, seria necessário concluir que os cidadãos são diferentes entre si em uma determinada medida que justificasse tal tratamento diferenciado.

Para o desenvolvimento desta discussão, faz necessária breve digressão sobre o tema dos bens públicos e sua exploração ao longo do tempo.

A discussão a respeito da superexploração dos bens públicos é marcadamente utilitarista, do ponto de vista filosófico. Não sob o argumento da utilidade do ato em si mesmo ("act utilitarianism") e suas consequências, mas sob a lógica da utilidade e consequências de uma ação coletiva em um determinado sentido ("rule utilitarianism" $)^{19}$.

A ideia de maximização da riqueza de uma sociedade, por sua vez, é a base do argumento da chamada Análise Econômica do Direito ${ }^{20}$. Para essa linha de

18 Sobre a importância dos princípios no estudo da dívida pública, ver PINTO, Élida Graziane. Controle da Administração do Endividamento Público, p. 332: “Mas por que é relevante abrir - em sede de estudo de caso sobre a dívida pública brasileira - a tematização sobre princípios constitucionais? Porque esses, além de representarem limites jurídicos que vinculam negativamente a ação do Estado, são verdadeiras 'directivas positivas', tal como bem assevera Canotilho (1994). Nessa hipótese, os princípios constitucionais operam como fundamento material que conforma a adequação constitucional de leis, atos administrativos e decisões judiciais."

19 WACKS, Raymond. Op. cit., p. 93: Sobre essa distinção ver: "It is important to note that utilitarians distinguish between 'act utilitarianism' (the rightness or wrongness of an action is to be judged by the consequences, good or bad, of the action itself) and 'rule utilitarianism' (the rightness or wrongness of an action is to be judged by the goodness or badness of the consequences of a rule that everyone should perform the action in like circumstances)."

20 WACKS, Raymond. Op. cit., p. 97: "Moreover, Posner argues, courts frequently decide difficult cases by choosing an outcome which maximizes the wealth of society. By 'wealth maximization' Posner means a situation in which goods and other resources are in the hands of those people who value them most; that is to say, those people who are willing (and able) to pay more to have them." 
pensamento, o valor de uma solução jurídica depende da sua eficiência econômica, isto é, da sua capacidade de gerar maximização da riqueza coletiva, no sentido de alocar os bens àqueles indivíduos que deles obtém o maior valor pessoal. Embora este raciocínio seja frequente na atividade de elaboração e avaliação de políticas públicas, é menos frequente no raciocínio jurídico levado a cabo pelos tribunais, que, em maior medida, deparam-se com conflitos de ordem individual ou que afetam pequenos grupos de indivíduos.

Diante desse quadro, nota-se como relevante observar que a aplicação do princípio da igualdade leva, em uma análise intertemporal, à necessidade de observância dos postulados normativos da razoabilidade e da proporcionalidade na aplicação das regras que autorizam ao endividamento público, de maneira a preservarem-se os interesses das futuras gerações na tomada de decisões de política fiscal das gerações presentes ${ }^{21}$.

A ideia de justiça entre gerações traz em si implícita a noção de que as diversas gerações possuam interesses por vezes contraditórios ou, no mínimo, diversos. Se assim não fosse, a questão se resumiria a uma questão de racionalidade econômica, em busca da melhor taxa intertemporal de poupança, de maneira a maximizar no tempo, o produto econômico e, por conseguinte, o produto per capita ${ }^{22}$.

Porém, mesmo se aceitando a existência de interesses diversos nas diferentes gerações, ainda assim seria necessário se discutir como se divisam as gerações. Ora, se o tempo é uma variável contínua e não discreta, isso implica dizer que, por mais que seja frequente tratar de gerações como se fossem facilmente identificáveis, não é simples identificar claramente interesses conforme gerações, simplesmente porque as gerações não são facilmente identificáveis ${ }^{23}$.

21 Segundo Ávila, os postulados normativos são normas de segundo grau que instituem critérios de aplicação de outras normas, situadas estas no plano do objeto de aplicação. Assim, podem ser identificadas como "metanormas", isto é, normas que tratam do método de aplicação de outras normas. (ÁVILA, Humberto. Op. cit., p. 164.)

Como ensina Ávila, a proporcionalidade, a razoabilidade e a eficiência não são propriamente princípios, mas sim postulados normativos aplicativos, no sentido em que se destinam a orientar a aplicação das normas. Assim, não é certo dizer que o princípio da eficiência ou da razoabilidade tenham sido violados por uma determinada decisão, mas sim que algum outro princípio foi violado, em virtude de sua aplicação ou afastamento ter se dado de forma ineficiente, desarrazoada ou desproporcional. (ÁVILA, Humberto. Op. cit., pp. 176-7.)

22 PAZ FERREIRA, Eduardo M. H. Da dívida pública e das garantias dos credores do Estado, pp. 70-72.

${ }^{23}$ PAZ FERREIRA, Eduardo M. H. Op. cit., p. 80: "Dificuldades suplementares surgem, no entanto, em torno da definição daquilo que se deve entender exatamente por geração, dado que, 
Esta dificuldade inclusive levou alguns doutrinadores a afirmarem ser impossível a identificação das gerações, sendo possível apenas determinar o grupo de cidadãos que efetivamente suportou os custos de determinadas políticas fiscais. Essa posição, porém, não é majoritária na doutrina, que se mantém apegada à ideia de gerações, ainda que por vezes formulando a questão sobre bases conceituais que se revelam consideravelmente abstratas e desprovidas de base na realidade ${ }^{24}$.

Um conceito interessante para a ideia de geração a identifica com todos aqueles sujeitos que participam de uma decisão financeira, sendo a geração seguinte formada pelos sujeitos que ou não existiam ainda no momento da decisão, ou ainda não possuíam condições jurídicas de participar da tomada de decisão em razão da idade ${ }^{25}$.

No mesmo contexto de análise, vale observar a linha de raciocínio desenvolvida por John Rawls. O critério de justiça proposto por este autor baseia-se em critério de decisão sob incerteza comum na literatura administrativa ${ }^{26}$, qual seja

embora se trate de um conceito corrente na linguagem comum, está longe de se poder pensar que foi sempre usado no mesmo sentido na polémica sobre os efeitos da dívida pública."

${ }^{24}$ PAZ FERREIRA, Eduardo M. H. Op. cit., pp. 80-1: "A dificuldade de determinação das fronteiras de cada geração levou, aliás, a que Griziotti afirmasse que estávamos em presença de uma pura abstracção e que não seria possível definir geração, mas tão só determinar, caso a caso, qual a massa de contribuintes que, efectivamente, suportou o custo de uma determinada despesa pública. Trata-se, contudo, de uma posição isolada, já que a generalidade dos autores que se debruçou sobre esta matéria sentiu a necessidade de utilizar um conceito de geração e o desenvolvimento da polémica sobre os efeitos intergeracionais levou a uma reelaboração do conceito em termos que, por vezes, parecem afastar-se totalmente da realidade."

25 PAZ FERREIRA, Eduardo M. H. Op. cit., p. 82: "Entendemos, assim, por geração presente, a totalidade dos indivíduos que, directamente ou por intermédio dos seus representantes, participam numa decisão financeira, e por gerações futuras, todas as restantes, quer integrem indivíduos já nascidos mas que ainda não têm idade para participar na decisão, quer aqueles que ainda não existem.”

${ }^{26}$ Para um exemplo de aplicação do critério não probabilístico de escolha sob incerteza "max-min" no campo da administração, ver, por exemplo, RAGSDALE, Cliff T. Spreadsheet modeling and decision analysis: a practical introduction to management science, p. 692: "A more conservative approach to decision making is given by the maximin decision rule, which pessimistically assumes that nature will always be 'against us' regardless of the decision we make. This decision rule can be used to hedge against the worst possible outcome of a decision. (...) To apply the maximin decision rule, we first determine the minimum possible payoff for each alternative and then select the alternative with the largest minimum payoff (or the maximum of the minimum payoffs - hence the term 'maximin'). (...)". 
o critério maxi-min, isto é, escolher a alternativa que maximiza/melhora o resultado no pior cenário. O raciocínio de Rawls parte da ideia de que, sob um comportamento estritamente individualista, mas partindo de situação de completa ignorância a respeito da posição social de cada indivíduo, a decisão de distribuição de recursos mais racional e, sob este critério, justa, seria a alternativa de distribuição que melhorasse ao máximo a condição daquele indivíduo em pior condição. Ao se proceder desta forma, seria também obtida a maior igualdade material possível $^{27}$.

Entre os princípios de justiça que Rawls argumenta que seriam escolhidos sob a condição que ele chama de "véu da ignorância", encontra-se o "princípio da poupança justa”. Este princípio tem direta correlação com o problema do conflito intergeracional e correlacionaria o nível justo de poupança àquele nível que seria adotado por um indivíduo sem conhecimento de em que época ou país viria a nascer e viver, sob a premissa de que todos os demais indivíduos e as demais gerações, antes e depois de sua existência adotassem o mesmo nível de poupança ${ }^{28}$.

27 WACKS, Raymond. Op. cit., p. 101: "Rawls presents an imaginary picture of the people in the 'original position', shrouded in a 'veil of ignorance', debating the principles of justice. They do not know their gender, class, religion, or social position. Each person represents a social class, but they do not know whether they are intelligent or dim, strong or weak, or even the country or period in which they are living. And they have only certain elementary knowledge about the laws of science and psychology.

In this state of almost perfect ignorance, they are required unanimously to choose the general principles that will define the terms under which they will live as a society. In this process they are motivated by rational self-interest: each seek those principles which will give him or her (but they are unaware of their gender!) the greatest opportunity of accomplishing his or her chosen conception of the good life. Stripped of their individuality, the people in the original position will select, says Rawls, a 'maxmin' principle (...)”

${ }^{28}$ RAWLS, John. Uma teoria da justiça, p. 359: "Quando analisam esse problema, as partes não sabem a que geração pertencem ou, o que acaba sendo a mesma coisa, em que estágio da civilização sua sociedade se encontra. Não tem como saber se essa sociedade é pobre ou relativamente rica, mais agrícola do que industrializada, e assim por diante. O véu de ignorância é completo nesses aspectos. Porém, já que interpretamos a posição original como se fosse adotada no momento presente $(\mathbb{2} 24)$, as partes sabem que são contemporâneas; e assim, a não ser que modifiquemos nossos pressupostos iniciais, não há motivo para que concordem em fazer qualquer tipo de poupança.

As gerações anteriores terão ou não poupado; não há nada que as partes possam fazer para alterar tal fato. Portanto, para alcançar um resultado razoável, supomos, em primeiro lugar, que as partes representam linhagens familiares, digamos, que se preocupam pelo menos com seus descendentes imediatos; e, em segundo lugar, que o princípio adotado deve ser tal que elas gostariam que as gerações anteriores o tivessem adotado $(\mathbb{2 2}$ ). Essas restrições, juntamente com o 
John Rawls parte do seu sistema de ideias para dele derivar um dever de agir no sentido de contribuir para o bem estar das gerações vindouras ${ }^{29}$. Tal derivação é decorrência da aceitação da existência de um contrato social implícito por meio do qual se assume a prevalência do valor liberdade e a aceitação da desigualdade apenas no sentido de melhorar a situação daqueles mais desfavorecidos na sociedade. Assim, qualquer pessoa racional, tendo que decidir sob o chamado 'véu da ignorância', sem saber, portanto, em qual geração teria de viver, concluiria pela vantajosidade de um sistema de regras sociais que privilegiasse o bem estar das gerações futuras ${ }^{30}$. Também tal posição, porém, foi alvo de críticas, principalmen-

véu da ignorância, têm por função garantir que qualquer geração se preocupe com todas as outras.”; WACKS, Raymond. Op. cit., p. 105: "Note that Rawls's second principle includes two significant limitations to secure the interests of the least advantaged. First, he introduces the 'just savings principle' which requires the people in the original position to ask themselves how much they would be willing to save at each level of the advancement of society, on the assumption that all other generations will save at the same rate. Remember that they have no idea which stage of civilization their society has reached. Consequently they will save some of their resources for future generations. The second limitation refers to the fact that jobs should be available to all."

29 Em KANT, Imannuel. A paz eterna e outros opúsculos, p. 23: "Causa sempre surpresa que as velhas gerações pareçam empenhar-se nas suas ocupações trabalhosas só em vista das futuras, para lhes preparar um estádio a partir do qual possam elevar ainda mais o edifício, que a natureza tem como intento, e que só as últimas gerações terão a sorte de habitar na mansão em que uma longa série dos seus antepassados (talvez, decerto, sem intenção sua) trabalhou, sem no entanto poderem partilhar da felicidade que prepararam. Mas se isto é assim tão enigmático, é ao mesmo tempo necessário, se alguma vez se supõe que uma espécie animal deve ter razão e, como classe de seres racionais, sujeitos à morte no seu conjunto, tem de chegar contudo à perfeição do desenvolvimento das suas disposições"

${ }^{30}$ RAWLS, John. Op. cit., p. 365: "Isso é suficiente para um breve esboço de algumas das principais características do princípio de poupança justa. Podemos agora ver que entre gerações há deveres e obrigações exatamente como entre contemporâneos. A geração atual não pode fazer o que bem lhe aprouver, mas é obrigada, por princípios que seriam escolhidos na posição original, a definir a justiça entre pessoas que vivem em épocas diferentes. Além disso, os homens têm um dever natural de apoiar a promover instituições justas e, para isso, é preciso aprimorar a civilização até certo nível. A dedução desses deveres e obrigações pode à primeira vista parecer uma aplicação forçada da doutrina contratualista. No entanto, essas exigências seriam reconhecidas na posição original e, portanto, a concepção da justiça como equidade as abrange sem nenhuma alteração de sua ideia fundamental.”; PAZ FERREIRA, Eduardo M. H. Op. cit., pp. 85-6: “O mesmo esquema interpretativo do 'véu de ignorância' é aplicado por Rawls à questão da distribuição temporal da riqueza, com a colocação dos indivíduos na posição original e em situação de ignorância quanto à geração em que irão viver, o que os conduzirá a dar uma resposta totalmente neutra, do ponto de vista do interesse das gerações, a qual consiste era aceitar que é obrigação de cada geração contribuir para o bem estar das gerações futuras, caso em que 
te em função da ideia de que a diferenciação em prol das gerações seguintes não estaria fundamentada em bases exclusivamente desinteressadas, como buscava ser a linha de raciocínio de Rawls ${ }^{31}$.

Contudo, se em bases estritamente racionais não se é capaz de formular uma teoria para sustentar o motivo pelo qual deveria haver uma solidariedade intergeracional, isto é, pelo qual deveria haver a valorização pela geração atual da necessidade de se gerar poupança para as gerações futuras, então, não haveria argumentos de natureza ética para se defender o progresso da sociedade. A não ser é claro que se aceite como válido o argumento de que o progresso seja, em si mesmo, um valor ético.

Sobre essa questão, portanto, divisam-se três linhas distintas de argumentação. Pela primeira linha, não haveria nenhuma obrigação entre gerações, senão a de preservar para a geração seguinte instituições justas e funcionais. Outra posição sustenta a ideia de que não poderia haver piora na situação de uma geração para outra, não havendo, porém, qualquer obrigação de melhora na situação. Finalmente, a terceira posição sustenta que haveria a obrigação de resguardar para as futuras gerações todos os ganhos gerados pela ação da geração em curso $^{32}$.

Em se adotando a posição de que as gerações carregam a responsabilidade de solidariamente contribuírem para o progresso geral, dividindo entre si os encargos da realização de uma sociedade justa, é preciso observar que o progresso geral não se identifica necessariamente com progresso material ${ }^{33}$. Daí a crítica que

ficarão sempre, num a situação de menor risco, independentemente da geração em que se venham a situar.

Todos os indivíduos colocados na posição original teriam, então, interesse na existência de um princípio da poupança justa, que levasse cada geração a assumir o dever de transmitir às seguintes uma dada quantidade de riqueza, estando assim estabelecidas as bases racionais para a cooperação intergeracional."

31 PAZ FERREIRA, Eduardo M. H. Op. cit., pp. 86-7.

32 PAZ FERREIRA, Eduardo M. H. Op. cit., p. 88: “Três grandes tipos de respostas parecem poder ser ensaiadas nesta matéria. Encontram-se elas na posição que sustenta que há apenas um dever de transmitir instituições justas e que funcionem, na que defende que a geração actual deve transmitir às futuras exactamente aquilo que recebeu das gerações que a antecederam e na que preconiza a existência de uma obrigação, por parte da geração presente de acrescer àquilo que recebeu, para transmitir uma herança complexiva superior às gerações sucessivas.”

33 RAWLS, John. Op. cit., p. 363: "Por fim, o último estágio em que se deve fazer poupança não se caracteriza por grande abundância. Talvez essa ponderação mereça algum destaque. O aumento da riqueza pode não ser supérfluo para alguns fins; e, de fato, talvez a renda média não seja muito alta, em termos absolutos. A justiça não exige que as gerações anteriores poupem para que as posteriores sejam meramente mais ricas. A poupança é exigida como uma condição para a realização plena de instituições justas e das liberdades iguais. (...)" 
se faz ao foco exclusivo nas despesas de investimento em capital físico como forma de preservação do patrimônio e construção da justiça intergeracional, excluindo-se por completo despesas meritórias como as realizadas em saúde, educação, cultura e lazer ${ }^{34}$.

A questão da impossibilidade de se aferir com segurança o interesse das gerações futuras e o fato de que a vontade das gerações atuais é manifestadas de maneira majoritária por meio de eleições periódicas das quais, por óbvio, as novas gerações não participam, põem em relevo a vantagem de se poder contar com regras estáveis que limitem o poder majoritário em defesa de presumíveis interesses das gerações vindouras ${ }^{35}$.

Fernando Facury Scaff considera a sustentabilidade financeira do Estado sob a perspectiva transindividual, aproximando o interesse dos cidadãos a essa sustentabilidade a interesses tais como o da manutenção de um meio ambiente ecologicamente equilibrado ${ }^{36}$. Assim a sustentabilidade financeira apresenta-se como uma dinâmica que envolve não apenas o presente, mas uma expectativa do por-

34 RAWLS, John. Op. cit., p. 362: "O processo de acumulação, uma vez iniciado e levado adiante, traz benefícios para todas as gerações subsequentes. Cada uma lega à outra um equivalente justo em capital real, que é definido por um princípio justo de poupança. (Devemos ter em mente que esse capital não consiste apenas em fábricas e máquinas etc., mas também no conhecimento e na cultura, bem como nas técnicas e habilidades, que tornam as instituições justas e o valor equitativo da liberdade possíveis.) Esse equivalente é uma retribuição pelo que foi recebido das gerações anteriores e possibilita que as posteriores vivam melhor em uma sociedade mais justa."; PAZ FERREIRA, Eduardo M. H. Op. cit., p. 51: “Não se deve, por outro lado, ignorar que o progresso das sociedade não depende apenas de aspectos materiais, pelo que se não poderá, por exemplo, pensar que a geração presente está puramente obrigada a investimento em bens de capital, podendo o investimento na cultura, na educação e no desenvolvimento geral do nível de vida das populações ter efeitos tanto ou mais benéficos para as futuras gerações.”

35 PAZ FERREIRA, Eduardo M. H. Op. cit., p. 93: A preocupação em assegurar a plena neutralidade dos decisores da geração actual não pode deixar de considerar que a circunstância de existirem mecanismos de controlo por parte da geração actual, expressos designadamente no processo eleitoral, pode levar a um sacrifício das gerações futuras, pelo que se pode colocar a questão de saber se se não deve garantir um quadro institucional limitativo das escolhas e que garanta a impermeabilidade do decisor às pressões de tipo eleitoral."

${ }^{36}$ SCAFF, Fernando Facury. Crédito Público e Sustentabilidade Financeira, p. 36: "O interesse protegido não é o da atual geração, mas sua preservação para as futuras gerações. Não é mais um interesse do indivíduo contra o Estado, ou inerente apenas a certa coletividade, mas um interesse difuso e que abrange não apenas as atuais, mas as futuras gerações. É esta nova dimensão dos direitos fundamentais que deve estar presente em nossa mente ao interpretar qualquer norma como um instrumento de sustentabilidade, e não como uma norma isolada em um ordenamento jurídico.” 
vir. Não é, portanto, um conceito avaliado em termos estáticos, mas sim com referência em uma convergência assintótica ${ }^{37}$.

Ainda que seja problemática a aferição do nível adequado de poupança, deve-se reconhecer a existência de um princípio de equilíbrio intergeracional, isto é, um princípio de "poupança justa”, para utilizar a expressão de John Rawls, como expressão do princípio da igualdade. Não há qualquer dispositivo, na Constituição brasileira, que autorize tratamento distinto entre gerações, sendo esse o fundamento para a proteção do meio ambiente, por exemplo, e o fundamento para a ideia de não retrocesso na proteção e na eficácia dos direitos fundamentais.

Se se pode discutir que os interesses da geração futura não devem se sobrepor aos da geração atual, também é fato que esses interesses não devem ser desconsiderados, estando o processo jurídico-político de decisão financeira sujeito a esse mandamento de maximização de um estado de coisas de equidade entre gerações, sob condições mínimas de gozo da liberdade e de instituições justas.

A existência, portanto, do princípio de equilíbrio intergeracional é evidenciada em todo o capítulo da Constituição dedicado às finanças públicas e também em outros trechos, ao impor regras restritivas ao superendividamento público, salientar o papel preponderante do planejamento na função orçamentária, e orientar os gastos públicos prioritariamente para setores que geram retornos sociais em escalas temporais mais alargadas, como é o caso dos gastos em educação.

\section{O MECANISMO DE DESLOCAMENTO DOS GASTOS PELO ENDIVIDAMENTO}

O recurso ao endividamento público tem por consequência o deslocamento temporal das despesas em relação ao produto delas decorrente ${ }^{38}$. Por consequên-

37 SCAFF, Fernando Facury. Op. cit., p. 40: "Sustentabilidade financeira é um conceito mais amplo que equilíbrio orçamentário, na leitura contábil-matemática do termo. Para que ocorra sustentabilidade financeira é necessário que seja estabelecido um período de tempo de médio e longo prazo, e que todos os elementos financeiros que estejam à disposição daquele ente público sejam analisados de forma conjunta, podendo mesmo haver déficits públicos periódicos visando alcançar certas metas sociais, e obter o necessário equilíbrio orçamentário, dentro do período de tempo estabelecido. Trata-se de uma análise dinâmica do fenômeno financeiro, e não uma análise estática, limitada a um período de 12 meses. Esta noção e sustentabilidade financeira está mais próxima de um filme que de uma fotografia, esta mais condizente com a lógica do equilíbrio orçamentário considerado como uma equação contábil-matemática.”

38 BALEEIRO, Aliomar. Introdução à ciência das finanças, p. 599: "Uma velha concepção, geralmente aceita, a ponto de tornar-se popular, quer que os préstimos públicos sejam a técnica pela qual as gerações futuras partilham de despesas da atualidade. Os financistas, que comun- 
cia, tornam-se disponíveis recursos no presente, contra a obrigação futura de retornarem, normalmente, contra o pagamento de juros e outros encargos financeiros. Por conta dessa dinâmica, o endividamento público suscita debate a respeito dos requisitos para que se opere tal deslocamento, sem que se incorra em violação de direitos das gerações subsequentes.

No campo das despesas públicas, o tipo de despesa que mais remete à questão intergeracional é o dos investimentos em infraestrutura, por implicarem em projetos demasiadamente caros, com cronogramas que podem superar décadas desde a fase de concepção até a fase de implantação e operação, e cujos benefícios apenas amortizarão os investimentos ao longo também de décadas ${ }^{39}$.

É preciso atentar, porém, que não apenas os benefícios serão diferidos, mas também no futuro serão sentidos os custos de operação e manutenção da infraestrutura instalada ${ }^{40}$. Assim, pode-se dizer que uma geração está a contratar não apenas os benefícios da infraestrutura, mas também os seus custos para a futura

gam dessa opinião, classificam, então, o crédito público como processo de repartição de encargos governamentais no tempo, em contraste com a tributação, que divide os mesmos gravames apenas entre indivíduos e classes do presente."

39 GREMAUD, Amaury P.; TONETO Jr., Rudinei. Descentralização e endividamento municipal: formas, limites e possibilidades, p. 112: “A principal justificativa no que tange ao endividamento para fins de investimento é a eficiência alocativa no longo prazo. De modo geral, o acesso ao mercado financeiro aumenta a eficiência econômica ao melhorar a alocação de recursos, tanto em termos intertemporais como setoriais. O endividamento é uma forma adequada de financiar as despesas de capital, uma vez que os benefícios deste tipo de despesa estão distribuídos ao longo do tempo e a dívida permite distribuir também seu custo ao longo do tempo, gerando assim eficiência em termos intergeracionais, ou seja, possibilitando a compatibilização do período de consumo do serviço com o de pagamento.” Ver também CARVALHO, André Castro. Direito da infraestrutura: perspectiva pública, p. 503: "Quando se trata do tema 'infraestrutura', a questão intergeracional faz-se presente mais do que em outras searas - principalmente por se tratar de bens com longo prazo de amortização, o que não costuma ocorrer em qualquer âmbito de ação governamental."

40 CARVAlHO, André Castro. Op. cit., p. 504: "A aquisição de capital novo tem alguns efeitos especiais, conforme aventado pela doutrina. O principal, nesse momento de análise, é destacar que há a produção de benefícios e a respectiva necessidade de manutenção por vários períodos subsequentes, ressaltando a faceta intertemporal ou intergeracional da infraestrutura. Dessa forma, '[...] uma perspectiva de planejamento a longo prazo é necessária para se ter em consideração a natureza intertemporal das decisões sobre capital.' Ademais, as próprias infraestruturas duram períodos que atravessam gerações, o que pode justificar a questão intergeracional no seu custeio, porquanto muitas gerações, o que pode justificar a questão intergeracional no seu custeio, porquanto muitas gerações beneficiar-se-ão do estoque criado." 
geração, sendo crucial que esta decisão se dê de forma transparente e em conformidade com um amplo planejamento de longo prazo, que referencie uma estratégia de desenvolvimento que abarque todas as áreas ${ }^{41}$.

Diferir as despesas não significa imediatamente alocá-las aos efetivos beneficiários diretos, mas apenas alocá-las em tempo futuro. Isto ocorre, pois, primeiramente, é possível que as condições de endividamento não permitam conciliar perfeitamente o cronograma físico de uma obra pública com o cronograma de desembolsos de uma dívida contratada. Em segundo lugar, é possível que mesmo no futuro não sejam os usuários da infraestrutura os seus únicos financiadores. Isso ocorrerá, por exemplo, quando a infraestrutura tiver uso predominante por um determinado grupo de cidadãos, seja pela sua natureza ou localização. Neste caso, poderemos falar de solidariedade intrageracional ou simplesmente de concentração sub-reptícia de renda ${ }^{42}$.

As despesas de capital idealmente devem ser planejadas no sentido de que o custo de implantação da infraestrutura seja suportado ao longo da vida útil da estrutura gerada pelo investimento. Esta regra se sustenta por razões de eficiência econômica, mas também por razões de equidade, permitindo que o custo de implantação da estrutura seja suportado pela geração de cidadãos que dela se beneficiam $^{43}$.

${ }^{41}$ CARVAlHO, André Castro. Op. cit., pp. 504-5: “O crédito público é, portanto, uma forma de envolver tanto os atuais contribuintes quanto os futuros em projetos de longo prazo. O problema é que, idealmente, a decisão pelo endividamento deveria ser de cunho econômico e levar em conta as receitas auferidas e o tamanho da dívida, juntamente com a relação intergeracional desses dois fatores - o que, na prática, costuma não ser a regra."

42 CARVAlHO, André Castro. Op. cit., p. 507: "Na Espanha, havia uma crítica ao modelo adotado para investimento em infraestrutura, já que estaria muito fulcrado no arrolamento da dívida oriunda das obras públicas, não estando o financiamento a cargo dos usuários, mas sim dos contribuintes futuros."

43 WORLD BANK INSTITUTE. Municipal finances: a learning program for local governments, p. 7: "The Golden Rule of capital finance is that, on both efficiency and equity grounds, the payment for capital goods should be spread over their useful life. It therefore follows that a financing mechanism be established so that the future generations that benefit from today's capital spending for infrastructure will pay for the benefits they derive from using it. Local governments must be allowed to borrow and take on debt that is financed over time, if their financial situation is in good standing." OLIVEIRA, Weder de. Curso de responsabilidade fiscal: direito, orçamento e finanças públicas, p. 76: "A obtenção de recursos de terceiros por meio de empréstimos e financiamentos é instrumento apropriado para financiar o investimento público, promove a equidade entre as gerações, representa opção de investimento para poupadores (mediante a aquisição de títulos públicos) e é fonte de recursos adequada para o enfrentamento de situações emergenciais e extraordinárias". 
A chamada "regra de ouro", neste contexto, apresenta restrições importantes em matéria de justificativa do endividamento público, não representando, contudo, de forma isolada, uma condicionante suficiente para um recurso adequado ao endividamento como forma de financiamento da ação estatal. Representando limitação à contratação de operações de crédito em nível superior às despesas de capital executadas, essa regra tem por objetivo canalizar as receitas decorrentes de operações de crédito para ações orçamentárias que, supostamente, são realizadas uma única vez, não deixando despesas continuadas para serem pagas indefinidamente. Ademais, supõe-se que as despesas de capital apresentem um retorno social superior às receitas correntes, o que, embora em linha com a visão tradicional que associa crescimento econômico ao estoque de capital físico de uma economia, vem sendo contestado na literatura econômica, que vem dando relevo especial aos investimentos em capital humano ${ }^{44}$.

A insuficiência da regra de ouro ocorre especialmente nos casos de entes públicos cuja demanda por infraestrutura é superior à oferta de crédito, sendo necessário recorrer à própria poupança para custear uma parte dos investimentos. Neste caso, será possível respeitar a regra de ouro e ainda assim destinar recursos para despesas correntes, simplesmente destinando a poupança corrente que, de outra forma financiaria investimentos, para o custeio de despesas correntes, passando os recursos oriundos de dívida a exercer o papel que antes seria realizado pela poupança corrente. Neste cenário, porém, o investimento total não se altera em relação ao que seria observado sem o endividamento ${ }^{45}$. No meio financeiro-burocrático, essa prática leva o curioso nome de "jogo de fontes".

${ }^{44}$ LUCAS JR. Robert E. On the mechanics of economic development. Journal of monetary economics, p. 39: "The model that I think is central was developed in section 4. It is a system with a given rate of population growth but which is acted on by no other outside or exogenous forces. There are two kinds of capital, or state variables, in the system: physical capital that is accumulated and utilized in production under a familiar neoclassical technology, and human capital that enhances the productivity or both labor and physical capital, and that is accumulated according to a 'law' having the crucial property that a constant level of effort produces a constant growth rate of the stock, independent of the level already attained."; SACHS, Jeffrey D.; LARRAIN B., Felipe. Macroeconomia, p. 612: "Estudos recentes do crescimento econômico sugerem que o papel do capital, incluindo o capital humano (investimentos nas habilidades do trabalhador), é maior do que o medido pelo esquema de crescimento de Solow. A ideia básica dessa nova pesquisa é que o investimento de capital, seja em máquinas seja em pessoas, cria externalidades positivas, isto é, o investimento aumenta não somente a capacidade produtiva de outras empresas e trabalhadores similares. (...)"

45 TER-MINASSIAN, Teresa; CRAIG, Jon. Op. cit., p. 171: "In principle, a good case can be made for limiting all borrowing to investment purposes. However, the so-called golden rule may 
Feitas essas considerações, observa-se que o recurso ao endividamento público deve ser precedido de cuidadosa análise de custo benefício dos gastos a serem financiados, o que nem sempre se observa, especialmente, no casa de abundância de liquidez e de crédito, com oferta de recursos a taxas de juros baixas. Isto, pois, nessas circunstâncias, projetos com retorno financeiro ou social reduzido passam a ser viáveis, resultando em contratações que, a longo prazo, poderão se mostrar más decisões do ponto de vista econômico, ou mesmo político e social ${ }^{46}$.

A experiência, porém, demonstra que as contratações de operações de crédito nem sempre são precedidas de cuidadosa preparação de projetos e avaliação dos custos sobre as gerações seguintes à sua contratação. Se isso é verdade para as operações de crédito, com ainda mais força se pode fazer tal afirmação para o caso de operações estruturadas que possam gerar endividamento público, sem, contudo, se confundirem com operações de crédito, no sentido jurídico da expressão, como é o caso das parcerias público-privadas ${ }^{47}$.

\section{A COMPETIÇÃO INTERGERACIONAL COMO TRAGÉDIA}

A questão do endividamento envolve uma discussão de justiça intergeracional, uma vez que se entende que os custos do financiamento para a criação de uma nova infraestrutura devem ser suportados ao longo do tempo, pelas gerações que se beneficiarão de fato da existência daquela estrutura ${ }^{48}$. O mesmo motivo é

not be sufficiently restrictive in countries that need to generate government savings to finance at least a part of public investment. Moreover, it may not be desirable to allow government borrowing to finance investments that do not have an adequate rate of economic and social return. Finally, in practice it may be difficult to avoid circumvention of the rule through the inclusion in investments of certain expenditures for current purposes."

${ }^{46} \mathrm{O}$ mesmo fenômeno ocorre em empresas privadas, justificando a manutenção de estrita disciplina de capital, com pagamentos de dividendos extraordinários aos acionistas em momentos de maior elevação do caixa, de maneira a evitar menor rigor na análise de custo-benefício de projetos e a aprovação de políticas de remuneração inconsistentes com eventual virada no ciclo econômico. A lição das finanças corporativas, neste tema, pode e deve ser analisada pela economia do setor público, com repercussões no direito financeiro.

47 Não trataremos em maiores detalhes do tema neste trabalho, para não o tornar demasiadamente longo. Para o leitor interessado, remetemos ao nosso trabalho anterior ARELLANO, Luis Felipe Vidal. Parcerias público-privadas e endividamento público, passim.

48 BANCO INTERAMERICANO DE DESARROLLO (BID). Liderando el desarrollo sostenible de las ciudades: unidad temática gestión financiera subnacional, p. 28: "Financiamiento más eficiente y justo de la infraestructura, toda vez que los beneficios de este tipo de inversión recaen también sobre las generaciones futuras, las cuales también lidarán con los costos de su finan- 
também razão para se argumentar pela impossibilidade de financiamento de despesas correntes com recursos de operações de crédito ${ }^{49}$.

Por outro lado, a possibilidade de utilização oportunista do endividamento público como forma de financiar as despesas públicas é decorrência também de diversos argumentos. Seja pela tentação dos cidadãos, agindo sob o efeito da "ilusão fiscal" ou no típico caso de "tragédia dos comuns", seja pela tentação de políticos no tradicional conflito agente-principal ${ }^{50}$, a tendência a transferir os custos da ação do Estado sobre as gerações futuras ou sobre uma classe diversa de cidadãos de uma mesma geração existirá e prevalecerá, caso não haja meios normativos de desincentivar esse comportamento ${ }^{51}$.

ciamiento. La maduración de la deuda contraída debería coincidir con la vida económica de los activos involucrados. En la misma línea, la amortización de los pasivos debería coincidir con la depreciación de los activos a financiar."

49 BANCO INTERAMERICANO DE DESARROLLO (BID). Op. cit., p. 29: "Si los déficits fiscales se originan cuando el endeudamiento subnacional financia inversión de capital y crecimiento económico, ello no representa un problema; no obstante, de acuerdo con la experiencia, los déficits se han generado para financiar pérdidas operacionales, lo cual ha producido situaciones fiscales insostenibles."

${ }^{50}$ Sobre falhas de governo e conflito agente principal, ver STIGLITZ, Joseph E. Economics of the public sector, pp. 8-10: "while market failures led to the institution of major government programs in the 1930s and 1960s, in the 1970s and 1980s the shortcoming of many such programs led economists and political scientists to investigate government failure. Under what conditions would government programs not work well? Where the failures of government programs accidents, or did they follow predictably from the inherent nature of governmental activity? Are there lessons to be learned for the design of programs in the future?

There are four major reasons for the systematic failures of the government to achieve its stated objectives: the government's limited information, its limited control over private responses to its actions, its limited control over the bureaucracy, and the limitations imposed by political processes. (...)

3 Limited control over bureaucracy. Congress and state and local legislatures design legislation, but delegate implementation to government agencies. An agency may spend considerable time writing detailed regulations; how they are drafted is critical in determining the effects of the legislation. The agency may also be responsible for ensuring that the regulations are enforced. (...) In many cases, the failure to carry out the intent of Congress is not deliberate but rather a result of ambiguities in Congress's intentions. In other cases, problems arise because bureaucrats lack appropriate incentives to carry out the will of Congress. For instance, in terms of future job prospects, those in charge of regulating an industry may gain more from pleasing members of the industry than from pursuing consumer interests."

51 OLIVEIRA, Weder de. Curso de responsabilidade fiscal: direito, orçamento e finanças públicas, p. 63: "Por inúmeras razões, algumas delas referidas às teorias expostas anteriormente: os 
A tendência ao endividamento pode ser explicada pela dinâmica política, assim como também o pode a tentação ao default da dívida externa de uma nação. O motivo central para este comportamento se deve ao fato de que nem os credores internacionais, nem as gerações ainda não nascidas votam, sendo, portanto, menos relevantes os seus interesses para fins de maximização de $\operatorname{votos}^{52}$. O mesmo motivo poderia explicar a tendência aos desequilíbrios previdenciários, na medida em que as novas gerações não têm condição de expressar politicamente o seu descontentamento com o financiamento da aposentadoria das gerações precedentes que, por sua vez, têm grande peso político.

Como se pode observar a partir da discussão trazida, a dinâmica das escolhas públicas traz dificuldades específicas no que se refere à alocação intertemporal de recursos. Se por um lado haverá clara tendência à superexploração dos bens públicos presentes, levando a uma competição entre gerações pelas melhores condições de vida, por outro lado, o pacto social fundado na Constituição Federal brasileira, assim como em diversos países, prevê a necessidade de se observar solidariedade entre gerações, como forma de conferir eficácia ao princípio da igualdade.

O mecanismo da dívida pública é o instrumento jurídico e econômico por meio do qual se pode deslocar o ônus financeiro de um investimento para o futuro. Isso não significa, porém, que não haja por parte da geração que faz o investimento uma decisão de abdicar de consumo no momento presente em prol do interesse da geração seguinte. Isto, pois a dívida pública é formada a partir da canalização da poupança privada para o setor público ${ }^{53}$. Assim sendo, a única maneira de transladar o custo do investimento totalmente para a geração seguinte, sem sacrifícios pela geração presente consistiria no recurso ao endividamento externo, uma vez que, neste caso, socorre-se da poupança externa, permitindo que o nível de consumo da geração presente interna se mantenha intocado.

benefícios dos gastos governamentais são diretamente usufruídos pelo público-alvo dos programas, enquanto os custos a eles associados são diluídos entre os milhões de atuais e futuros contribuintes; a maioria dos atuais beneficiários são eleitores e parte dos que arcarão com parcela dos custos no futuro ainda não o são; os políticos direcionam as suas ações pelos próprios interesses, em vez de fazê-lo pelos interesses daqueles que os elegem; uma vez que o orçamento público utiliza recursos aportados por todos, há incentivos para que cada grupo atue para extrair desse fundo comum mais do que deveria estar prudentemente a eles disponível; o crescimento da concessão de benefícios de natureza obrigatória torna o gasto público mais difícil de ser gerenciado e aumenta o custo político de obter o equilíbrio orçamentário."

52 OLIVEIRA, Weder de. Curso de responsabilidade fiscal: direito, orçamento e finanças públicas, p. 76.

${ }_{53}$ É a partir dessa constatação que a literatura econômica define a ideia de crowding out. 
Não é preciso grande elaboração para que se reconheça que o estabelecimento de uma competição entre gerações não leva a bom termo, pelo simples fato de que as gerações vindouras não possuem mecanismos para se defender. Esse problema aparece muito claramente na discussão do direito ambiental, especialmente no que se refere ao combate às mudanças climáticas decorrentes da emissão exagerada de gases causadores do efeito estufa.

No caso do endividamento público, a relação não é tão evidente, embora seja tão forte quanto no caso mencionado da proteção ao meio ambiente. É preciso, portanto, que o direito financeiro e o direito econômico apresentem instrumentos adequados de tratamento da questão, de maneira a dar plena eficácia à proteção das diversas gerações, combatendo a tendência à competição que se estabeleceria em condições normais.

A chamada "tragédia dos comuns" é descrita, no trabalho inaugural de Garret Hardin, por meio da analogia dos criadores de rebanhos particulares que dividem um mesmo pasto. Como o ganho marginal de acrescentar um animal ao seu rebanho é superior ao custo para o pasto, que é fracionado por todos os criadores, todos eles tenderão a superexplorar esse recurso, acrescentando cada vez mais animais ${ }^{54}$.

A tragédia dos comuns, segundo o autor, não ocorre no caso de bens privados, sendo a propriedade privada, portanto, uma forma de lidar com o reduzido custo marginal de utilização de bens públicos. Ocorre, contudo, que nem todos os bens podem ser transformados em privados, o que é verdade, por exemplo, para o ar que respiramos. Neste caso, seria necessário adotar outros tipos de medidas, tais como regulação (simplesmente proibindo ou obrigando condutas) ou taxação (aumentando o custo marginal de utilização do bem público) $)^{55}$.

O apelo à consciência das pessoas, neste contexto, não é suficiente para evitar a superexploração dos recursos públicos. Isto, pois as pessoas respondem de formas diferentes a esse apelo e, no longo prazo, as pessoas que não agem de forma altruísta teriam mais vantagens que as pessoas que agem atendendo ao apelo da consciência. Assim, a hipocrisia da maioria levaria a uma situação de equilíbrio de longo prazo que manteria a superexploração dos recursos ${ }^{56}$.

${ }_{54}$ HARDIN, Garret. The tragedy of the commons, p. 1244.

55 HARDIN, Garret. Op. cit., p. 1245.

${ }^{56}$ HARDIN, Garret. Op. cit., p. 1246: "The long-term disadvantage of an appeal to conscience should be enough to condemn it; but has serious disadvantages as well. If we ask a man who is exploiting a commons to desist 'in the name of conscience,' what are we saying to him? What does he hear? -- not only at the moment but also in the wee small hours of the night when, half 
No caso do endividamento público, é possível estabelecer um paralelo entre a situação dos criadores de rebanhos de Hardin e as diferentes gerações. Isoladas as considerações relativas à ideia de coletividade e de solidariedade entre gerações, o comportamento de cada geração tenderá a consolidação de uma situação de superendividamento, na exata medida em que os custos dessa situação possam ser repassados exclusivamente às gerações futuras. Assim, as situações excepcionais de ajustes, além de mais severas do que precisariam ser, apenas ocorreriam em momentos em que se mostrassem como inevitáveis diante da iminência de uma crise social gravíssima, daí serem tomadas como verdadeira tragédia em termos sociais e políticos.

\section{CONCLUSÕES}

Conforme se buscou demonstrar no presente trabalho, a análise do tema da dívida pública não pode prescindir de uma busca jusfilosófica a respeito do fundamento da transposição de despesas de uma geração para outra. Neste contexto, buscou-se discutir os desafios para a construção de uma ideia de princípio de equilíbrio intergeracional.

Em linha com o exposto, o fundamento constitucional para a existência de tal princípio residiria no artigo $5^{\circ}$, caput, da Constituição Federal, apresentando-se o princípio de equilíbrio intergeracional como um subprincípio do princípio da igualdade, refletindo a necessidade de respeito à igualdade entre gerações em direitos, abstendo-se as diversas gerações de agir em prejuízo das gerações seguintes, seja em matéria ambiental, como já há tempos se discute, mas também em matéria financeira.

Revela-se em face disso a necessidade de aprofundamento dos estudos relativos ao direito financeiro, com aperfeiçoamento da legislação brasileira no sentido de evitar situações de oportunismo que impliquem na assunção de encargos a serem cobertos pelas gerações futuras, sem a adequada justificativa em termos dos benefícios que serão aproveitados por essas gerações. Neste sentido, a simples utilização da chamada "regra de ouro", como disposta no texto constitucional brasileiro, ainda se apresenta como solução tímida e pouco efetiva para o tema.

asleep, he remembers not merely the words we used but also the nonverbal communication cues we gave him unawares? Sooner or later, consciously or subconsciously, he senses that he has received two communications, and that they are contradictory: (i) (intended communication) 'If you don't do as we ask, we will openly condemn you for not acting like a responsible citizen'; (ii) (the unintended communication) 'If you do behave as we ask, we will secretly condemn you for a simpleton who can be shamed into standing aside while the rest of us exploit the commons.'” 


\section{REFERÊNCIAS}

ARELLANO, Luis Felipe Vidal. Parcerias público-privadas e endividamento público. In: André Castro Carvalho; Leonardo F. de Moraes e Castro. (Org.). Manual de Project Finance no Direito Brasileiro. São Paulo: Quartier Latin, 2016.

ÁVILA, Humberto. Teoria dos princípios: da definição à aplicação dos princípios jurídicos. São Paulo: Malheiros, 2015.

BALEEIRO, Aliomar. Introdução à ciência das finanças. Rio de Janeiro: Forense, 2012.

BANCO INTERAMERICANO DE DESARROLLO (BID). Liderando el desarrollo sostenible de las ciudades: unidad temática gestión financiera subnacional. [s.1.]: BID, 2014.

CARVAlHO, André Castro. Direito da infraestrutura: perspectiva pública. São Paulo: Quartier Latin, 2014.

FERREIRA, Ivan Fecury Sydrião. A Economia Política do Endividamento Público em uma Federação: um estudo comparativo entre o Brasil e os Estados Unidos. São Paulo: EAESP/FGV, 1998. 77p. (Dissertação de Mestrado apresentada ao Curso de Mestrado em Administração Pública e Governo da EAESP/FGV, Área de Concentração: Planejamento e Finanças Públicas).

GIAMBIAGI, F.; ALÉM, A. Finanças Públicas: teoria e prática no Brasil. Rio de Janeiro: Campus, 2011.

GREMAUD, Amaury P.; TONETO Jr., Rudinei. Descentralização e endividamento municipal: formas, limites e possibilidades. Revista Nova Economia, Belo Horizonte, jul/dez 2002, pp. 109-130.

HARDIN, Garret. The tragedy of the commons, Science, v. 162, n. 3859, pp. 1243 1248, December 13, 1968.

KANT, Imannuel. A paz eterna e outros opúsculos. Lisboa: Editora 70, 2018.

LUCAS JR. Robert E. On the mechanics of economic development. Journal of monetary economics, n. 22, North Holland, 1988, pp. 3-42.

OLIVEIRA, Weder de. Curso de responsabilidade fiscal: direito, orçamento e finanças públicas. Belo Horizonte: Fórum, 2013.

PAZ FERREIRA, Eduardo M. H. Da dívida pública e das garantias dos credores do Estado. Coimbra: Almedina, 1995.

PINTO, Élida Graziane. Controle da Administração do Endividamento Público. Belo Horizonte: UFMG (Tese de Doutorado), 2006, p. 321-391.

RAGSDALE, Cliff T. Spreadsheet modeling and decision analysis: a practical introduction to management science. Virginia: Cengage Learning, 2012.

RAWLS, John. Uma teoria da justiça. São Paulo: Martins Fontes, 2016. 
SACHS, Jeffrey D.; LARRAIN B., Felipe. Macroeconomia. São Paulo: Person Education do Brasil, 2000.

SCAFF, Fernando Facury. Crédito Público e Sustentabilidade Financeira. Revista Direito à Sustentabilidade. Unioeste, v. 1, n. 1, 2014, pp. 34-47.

STIGLITZ, Joseph E. Economics of the public sector. New York: Norton, 1999. TER-MINASSIAN, Teresa; CRAIG, Jon. Control of subnational government borrowing. In TER-MINASSIAN, Teresa (ed.). Fiscal federalism in theory and practice. Washington: International Monetary Fund, 1997, pp. 156-172.

WACKS, Raymond. Philosophy of law: a very short introduction. Oxford: Oxford University [Kobo Edition], 2014.

WORLD BANK INSTITUTE. Municipal finances: a learning program for local governments. Module 01 Intergovernmental Finances in a Decentralized World (Printable course material). [s.l]: WB, [s.d]. 
